\title{
Establishment of an immortalized intestinal epithelial cell line from tree shrews by lentivirus-mediated hTERT gene transduction
}

\author{
Bowen Yin · Qingkai Song $\cdot$ Lingxia Chen $\cdot$ Xiaofei Li $\cdot$ Yuanyuan Han • \\ Xuan Wang $\cdot$ Jiejie Dai $\cdot$ Xiaomei Sun $(\mathbb{D}$
}

Received: 20 December 2017 / Accepted: 16 October 2018/Published online: 2 January 2019

(C) The Author(s) 2019

\begin{abstract}
The intestinal epithelium has an average lifespan of 4-5 days. Normally, primary intestinal epithelial cells can be cultured for about 15 days in vitro. The aim of this study was to explore methods to isolate and immortalize intestinal epithelial cells (IECs) of tree shrews in order to establish a new resource of experimental material and to provide a cell model for drug development and infection mechanism research. Tissue from the small intestine of tree shrews was digested with collagenase XI, neutral protease I, and dithiothreitol. The human telomerase reverse transcriptase gene ( $h T E R T)$ was transferred into tree shrew IECs using the pHBLV-CMVIE-ZsGreen-Puro vector. The level of hTERT mRNA was detected by quantitative reverse transcription polymerase chain reaction. Immunofluorescence and western blot assays were performed to detect biochemical markers of
\end{abstract}

Electronic supplementary material The online version of this article (https://doi.org/10.1007/s10616-018-0270-0) contains supplementary material, which is available to authorized users.

B. Yin $(\bowtie) \cdot$ Q. Song $\cdot$ L. Chen $\cdot$ X. Li

Y. Han $\cdot$ X. Wang $\cdot$ J. Dai $\cdot$ X. Sun $(\bowtie)$

Center of Tree Shrew Germplasm Resources, Institute of

Medical Biology, The Chinese Academy of Medical

Science, Peking Union Medical College, Jiaoling Road

935, Kunming 650118, China

e-mail: sxm@imbcams.com.cn

X. Sun

e-mail: 1023650688@qq.com
IECs. The micromorphology of cells was observed with electron microscopy. We then conducted experiments to assess proliferative activity and analyze the karyotype of isolated cells. The results showed the immortalized cell line that we established and screened, maintained the characteristics and biochemical markers of primary IECs. Our results showed that the cell line we established can be considered an alternative cell model for intestinal drug research and for studies on intestinal infection and cell signaling.

Keywords Immortalized $\cdot$ Intestinal epithelial cell line - Tree shrews - Lentivirus-mediated hTERT gene

\section{Introduction}

Tree shrews (Tupaia belangeri chinesis) are small mammals that are close relatives of primates and show a high degree of similarity to humans in their anatomy and physiology, neural development, and responses to viral infection and psychological stress (Xu et al. 2013). Compared with other non-primate mammals, tree shrews have a high brain-to-body mass ratio $(\mathrm{Xu}$ et al. 2012). Other characteristics, such as their small size, short breeding cycle, and low food and research costs make the tree shrew an ideal animal model.

The intestinal epithelium forms a natural physical barrier and maintains the structural stability of the 
intestine. However, the intestinal tract is exposed to a large number of antigens (Martini et al. 2017) and gut inflammation can easily disrupt the intestinal epithelium. Recent studies have revealed that the intestinal microenvironment is complex and that dysbiosis can result in various diseases (Tanaka and Nakayama 2017), including inflammatory bowel disease (Christopher et al. 2015), irritable bowel syndrome (Codling et al. 2010), obesity (Karimi et al. 2015), allergies (Lynch and Boushey 2016), autoimmune diseases, and brain disorders (Wang and Kasper 2014). Models of the intestinal epithelium are important for understanding these diseases. However, long-term in vitro culture of primary intestinal epithelial cells (IECs) is difficult because the epithelium is completely renewed every 4-5 days (van der Flier and Clevers 2009). Additionally, IECs are highly sensitive to anoikis, a form of programmed cell death caused by epithelial cell and extracellular matrix disorders. Therefore, better research models are needed to study IECs.

Telomeres are the repeating nucleotide sequence regions at the ends of chromosomes that protect them from deterioration or fusion with adjacent chromosomes (Witzany 2008). During the process of chromosome replication, DNA polymerase does not extend to the end of the chromosome, causing the ends to shorten after each DNA replication cycle. As telomeres become shorter they reach the theoretical Hayflick limit around 50-70 cycles of cell division, resulting in cell death (Hayflick1965). Telomerase is a polyprotein complex made up of a telomerase reverse transcriptase (TERT) catalytic subunit and a telomerase-associated RNA template that adds DNA repeats to the end of the chromosome to prevent telomere shortening (Blackburn 2001). However, human TERT (hTERT) is only expressed in telomerase-positive cells and, shortly after birth, telomerase activity ceases in most normal human tissues. Therefore, hTERT gene transfer has been used as a means of immortalizing cells, including human retinal epithelial cells (Bodnar et al.1998) and porcine small intestinal epithelial cells (Wang et al. 2014).

In this study, we successfully used a lentivirusmediated method to infect tree shrew primary IECs with the $h T E R T$ gene to create an immortalized cell line we called TIEC.

\section{Materials and methods}

Animals and reagents

Two-day-old neonatal tree shrews were reared in an environment with a temperature of $16-28{ }^{\circ} \mathrm{C}, 40-70 \%$ humidity, noise levels $\leq 60 \mathrm{~dB}$, and light intensity levels of 1001-1501 $\times$. Experimental animals were obtained from the Center of Tree Shrew Germplasm Resources, Institute of Medical Biology, Chinese Academy of Medical Science and Peking Union Medical College with the production license number SCXK (Yunnan) K2013-0001. The Institutional Animal Care and Welfare Committee of the Institute of Medical Biology, Chinese Academy of Medical Sciences and Peking Union Medical College approved the present study, and all procedures were performed according to ethical standards and practices.

The following reagents were used: dithiothreitol (DTT) (Biosharp), collagenase XI (catalog \# C7657, Sigma-Aldrich), insulin-transferrin-selenium (ITS-G; Life), epidermal growth factor (EGF; PeproTech), neutral protease I (Solarbio), D-sorbitol (Biosharp), pHBLV-CMVIE-ZsGreen-Puro vector (Shenggong Engineering Co., Ltd.), Escherichia coli DH5 $\alpha$ (Invitrogen), trypsin (Thermo), Dulbecco's Modified Eagle's Medium (DMEM; Thermo), phosphate buffered saline (PBS; HyClone), TaKaRa One Step PrimeScript RT-PCR Kit (Perfect Real Time) (Dalian Bao Bioengineering Co., Ltd.), RNeasy Mini Kit (Qiagen), PrimeScript II 1st Strand cDNA Synthesis Kit (Dalian Bao Bioengineering Co., Ltd.), Golden Green Mix (TsingKe), rabbit anti-cytokeratin 18 antibody (Abcam), anti-occludin antibody (Abcam), anti- $\beta$-actin antibody (Abcam), and puromycin (Solarbio).

Isolation and culture of tree shrew intestinal epithelial cells

Two-day-old tree shrews were euthanized by injecting an overdose of pentobarbital sodium. The small intestine was collected and prepared by removing the longitudinal muscle layer and washing with ice-cold Hank's Balanced Salt Solution (HBSS) wash solution containing $100 \mathrm{U}$ penicillin, $100 \mu \mathrm{g} / \mathrm{mL}$ streptomycin, $25 \mu \mathrm{g} / \mathrm{mL}$ gentamycin, and $0.5 \mathrm{mM}$ DTT in $\mathrm{Mg}^{2+}$. and $\mathrm{Ca}^{2+}$-free HBSS (Graves et al. 2014). The tissue was cut into small pieces and washed several times 
with HBSS wash solution until the supernatant was clear. The contents were allowed to settle for $10 \mathrm{~min}$ and the supernatant was discarded. The remaining tissue was placed in $10 \mathrm{~mL}$ of digestion buffer containing $1 \% \mathrm{v} / \mathrm{v}$ fetal bovine serum (FBS), $75 \mathrm{U} /$ $\mathrm{mL}$ collagenase XI, $20 \mu \mathrm{g} / \mathrm{mL}$ dispase neutral protease II, and $0.5 \mathrm{mM}$ DTT in DMEM. The tissue was digested in a $37{ }^{\circ} \mathrm{C}$ incubator with shaking at $180 \mathrm{rpm}$ for $2 \mathrm{~h}$. A $10-\mathrm{mL}$ dispersion solution (DMEM containing $2 \% \mathrm{w} / \mathrm{v} \mathrm{D}$-sorbitol) was then added to the digestion mixture and the tissue was disassociated by repeated pipetting. Remaining tissue debris was discarded and the supernatant containing proliferative crypts was centrifuged at $200 \times g$ for $8 \mathrm{~min}$. Cell pellets were washed twice in DMEM (high glucose) and resuspended in DMEM (high glucose) containing $10 \mathrm{mM}$ HEPES, $100 \mathrm{U} / \mathrm{mL}$ penicillin, $100 \mathrm{mg} / \mathrm{mL}$ streptomycin, $10 \mathrm{ng} / \mathrm{mL}$ EGF, 1\% ITS, and 2\% FBS and cultured at $37{ }^{\circ} \mathrm{C}$ and $5 \% \mathrm{CO}_{2}$. Media were changed every 3 days. FBS was adjusted to $10 \%$ when cells reached confluence after 10-12 days.

\section{Construction of lentiviral vector}

pHBLV-CMVIE-ZsGreen-Puro containing a ZsGreen gene and a puromycin resistance gene was selected as the vector for the exogenous hTERT gene. Primers were designed to amplify the $h T E R T$ gene sequence provided by the National Center for Biotechnology Information (NCBI) and EcoRI and XbaI restriction sites were added to the $5^{\prime}$ ends of the forward and reverse primers to create primers hTERT-EcoRI/ XbaI-F:5' -ggatctatttccggtgaattcgecaccATGCCGCG CGCTCCCCGCT-3' and hTERT-EcoRI/XbaI-R: 5'ggatccgcggccgcttctaga GTCCAGGATGGTCTTGAA GT-3'. The amplified $h T E R T$ gene and the vector were each cut with EcoRI and XbaI and joined by T4 ligase (Thermo). The constructed lentivirus vector was transformed into $E$. coli $\mathrm{DH} 5 \alpha$ to amplify the plasmid. Three plasmids, PSPAX2, pMD2G, and pHBLVCMVIE-ZsGreen-Puro, were then co-transfected into 293T cells to package the lentivirus. The culture supernatant from these cells was collected $48 \mathrm{~h}$ and $72 \mathrm{~h}$ after transfection and ultracentrifuged at $2000 \times g$ for $10 \mathrm{~min}$ at $4{ }^{\circ} \mathrm{C}$. Cell debris was discarded and the supernatant was transferred to a new tube and ultracentrifuged at $82,700 \times g$ for $120 \mathrm{~min}$ at $4{ }^{\circ} \mathrm{C}$. Lentivirus was aliquoted into sterilized tubes and stored at $-80{ }^{\circ} \mathrm{C}$.
The titer of virus was determined by the dilution and counting method. 293T cells were plated in 96-well plates at a density of approximately $1 \times 10^{5} \%$ $\mathrm{mL}(100 \mu \mathrm{L} /$ well $)$ and cultured at $37{ }^{\circ} \mathrm{C}$ and $5 \% \mathrm{CO}_{2}$. The virus solution was diluted three-fold and $10 \mu \mathrm{L}$ of each dilution was added to the 293T cells. Three days post-infection, wells that contained cells whose percentage of fluorescence was between 10 and $30 \%$ were used to calculate the virus titer using the following equation: titer $(\mathrm{TU} / \mathrm{mL})=$ cell number $\times$ fluorescence ratio $\times$ multiplicity of infection $(\mathrm{MOI}$; 1) $\times$ virus dilution factor $\times 10^{3}$.

\section{Transduction and screening}

IECs passaged to the third generation were plated onto 24-well plates at a density of $1 \times 10^{4}$ cells $/ \mathrm{mL}$. The media were discarded and $250 \mu \mathrm{L}$ of cell maintenance media $(10 \mathrm{mM}$ HEPES, $100 \mathrm{U} / \mathrm{mL}$ penicillin, $100 \mathrm{mg} / \mathrm{mL}$ streptomycin, $10 \mathrm{ng} / \mathrm{mL}$ EGF, and $1 \%$ ITS) were added. Cells were infected with lentivirus at an MOI of 10 and cultured at $37^{\circ} \mathrm{C}$. The percent fluorescence was determined with a fluorescence microscope $72 \mathrm{~h}$ post-infection.

To screen cells, $5 \mu \mathrm{g} / \mathrm{mL}$ puromycin was added to both experimental and control cells. When control cells were completely killed with $5 \mu \mathrm{g} / \mathrm{mL}$ puromycin $2.5 \mu \mathrm{g} / \mathrm{mL}$ puromycin was added to the corresponding experimental cells. Cells were then digested with trypsin and diluted to 10 cells $/ \mathrm{mL}$ in complete media and single cells $(0.1 \mathrm{~mL})$ were seeded into 96 -well plates. Wells that contained only one cell, as observed by microscopy, were marked and incubated in a $37{ }^{\circ} \mathrm{C}$ incubator to form monoclonal cells.

hTERT gene expression analysis by quantitative reverse transcription polymerase chain reaction (qRT-PCR)

RNA was extracted from transduced cells using an RNeasy Mini Kit (Qiagen) and reverse transcribed into cDNA using the TaKaRa One Step PrimeScript RTPCR Kit (Perfect Real Time) (Dalian Bao Bioengineering Co., Ltd.) according to the manufacturer's protocol. The following hTERT gene primers were designed based on the hTERT gene sequence: F: $5^{\prime}$ TCCGAGGTGTCCCTGAGTAT-3' and R: 5'-TGACACTTCAGCCGCAAGA-3'. qRT-PCR was carried out using a $2 \times$ T5 Fast qPCR Mix (SYBR Green I) 
kit (TsingKE). The reaction contained $10 \mu \mathrm{L} 2 \times \mathrm{T} 5$ Fast qPCR Mix, $0.8 \mu \mathrm{L}$ each upstream and downstream primer, $50 \times$ ROX Reference Dye I/II, and $0.4 \mu \mathrm{L} \mathrm{cDNA}(<100 \mathrm{ng})$. The following conditions were used for the qRT-PCR reaction: $95^{\circ} \mathrm{C}$ for $1 \mathrm{~min}$; 40 cycles of $95{ }^{\circ} \mathrm{C}$ for $10 \mathrm{~s}, 55^{\circ} \mathrm{C}$ for $5 \mathrm{~s}$, and $72{ }^{\circ} \mathrm{C}$ for $15 \mathrm{~s}$; and fluorescence signal acquisition at $72{ }^{\circ} \mathrm{C}$.

\section{Immunofluorescence microscopy}

Cells were fixed in $4 \%$ paraformaldehyde for $30 \mathrm{~min}$ at room temperature. Cells were then washed three times with PBS, permeabilized with $0.1 \%$ Triton $\mathrm{X}-100$ for $20 \mathrm{~min}$ at room temperature, and blocked with $1 \%$ bovine serum albumin for $30 \mathrm{~min}$. Cells were immunolabeled with anti-cytokeratin 18 antibodies (1:500) overnight at $4{ }^{\circ} \mathrm{C}$. Cells were then washed with PBS and incubated with goat anti-mouse $\mathrm{IgG}$ antibody (Abcam) at room temperature for $1 \mathrm{~h}$. After washing three times in PBS, cells were incubated with 4',6-diamidino-2-phenylindole (DAPI) diluted 1:500 in PBS for $5 \mathrm{~min}$ and imaged using fluorescence microscopy.

\section{Western blotting}

Once confluent, cells grown in six-well plates were rinsed with PBS. Cell lysis buffer containing $1.0 \mathrm{mmol} / \mathrm{L}$ phenylmethanesulfonyl fluoride was added and the mixture was boiled for $10 \mathrm{~min}$. Proteins were separated with sodium dodecyl sulfate polyacrylamide gel electrophoresis on a $12 \%$ gel, transferred to a polyvinylidene fluoride (PVDF) membrane at $15 \mathrm{~V}$ for $1 \mathrm{~h}$, and washed three times with PBS. The PVDF membranes were blocked with skim milk at room temperature for $1 \mathrm{~h}$ and washed three times with PBS containing $0.5 \%$ Tween 20 (PBST). PVDF membranes were incubated overnight with anti- $\beta$-actin antibody or the primary antibodies anti-cytokeratin 18 and anti-occludin diluted in skim milk at $4{ }^{\circ} \mathrm{C}$ and washed three times with PBST. Membranes were then incubated with secondary antibodies (1:5000) for $1 \mathrm{~h}$ at room temperature, washed three times with PBST, and photographed using a gel imager (Bio-Rad).

Transmission electron microscopy

Cells were centrifuged, fixed with $2.5 \%$ glutaraldehyde, dehydrated, embedded, and sectioned. The ultrastructure of cells was observed using a transmission electron microscope following the protocol of Geens and Niewold (2011).

\section{Cell growth curves}

Primary tree shrew intestinal epithelial cells (pTIECs) and transduced cells were plated onto 24-well plates at $1 \times 10^{4}$ cells per well and incubated at $37{ }^{\circ} \mathrm{C}$ and $5 \%$ $\mathrm{CO} 2$. One well of cells was digested with $0.25 \%$ trypsin every $24 \mathrm{~h}$ and transferred to a $1.5 \mathrm{~mL}$ centrifuge tube. Cells were counted using a hand-held cell counter. Experiments were conducted in triplicate and mean values were plotted for growth curves. Differences between groups were examined for statistical significance using the Student's $t$ test. $P<0.05$ was considered as statistically significant.

\section{Optimal FBS concentration determination}

Cells were seeded into 96 -well plates at $2 \times 10^{3}$ cells per well and incubated for $36 \mathrm{~h}$ at $37{ }^{\circ} \mathrm{C}$ in complete media containing $0,2,5,10$, or $20 \%$ FBS. Cell proliferation was measured using the WST-1 Cell Proliferation and Cytotoxicity Assay Kit (Beyotime) and mean values were plotted using histograms. Experiments were conducted in triplicate. Differences between groups were examined for statistical significance using the Student's $t$-test.

Karyotype analysis

Cells were washed with PBS and centrifuged at $1500 \mathrm{rpm}$ for $5 \mathrm{~min}$. The supernatant was discarded and cells were washed with PBS for $1 \mathrm{~min}$ and centrifuged at $300 \times g$ for $5 \mathrm{~min}$. The supernatant was discarded and the cell pellet was resuspended in $75 \mathrm{mmol} / \mathrm{L} \mathrm{KCl}$ and allowed to settle for $8 \mathrm{~min}$ at room temperature. One drop of methanol:glacial acetic acid (3:1) fixative was added and the sample was centrifuged at $300 \times g$ at $4{ }^{\circ} \mathrm{C}$. The supernatant was discarded and $1 \mathrm{~mL}$ fixative was added to the sample. The sample was allowed to settle for $30 \mathrm{~min}$ at $4{ }^{\circ} \mathrm{C}$, resuspended, and centrifuged at $300 \times g$ at $4{ }^{\circ} \mathrm{C}$. The supernatant was discarded and $500 \mu \mathrm{L}$ fixative was added to the sample. The sample was resuspended, dropped onto a clean slide precooled to $4{ }^{\circ} \mathrm{C}$, and air dried. Samples were stained with Giemsa dye for $10 \mathrm{~min}$ and observed under a microscope. 


\section{Results}

\section{Monoclonal TIEC screening}

After infection with lentivirus, cells were continuously observed using fluorescence microscopy. Fifteen days post-infection, the number of cells was higher and the fluorescence was stronger than on the fifth day (Fig. 1a, b), indicating that the ZsGreen gene carried by the vector was expressed.

For isolation of transformed cells, cells were digested and transferred to 96-well plates 15 days post-infection. Three wells were found to contain one cell (Fig. 1c, d) named TIEC1, TIEC2, TIEC3 respectively. As the three clones showed no significant differences in the following experiments, TIEC1 was selected and mainly discussed here. The results of TIEC2 and TIEC3 are shown in supplementary figures.
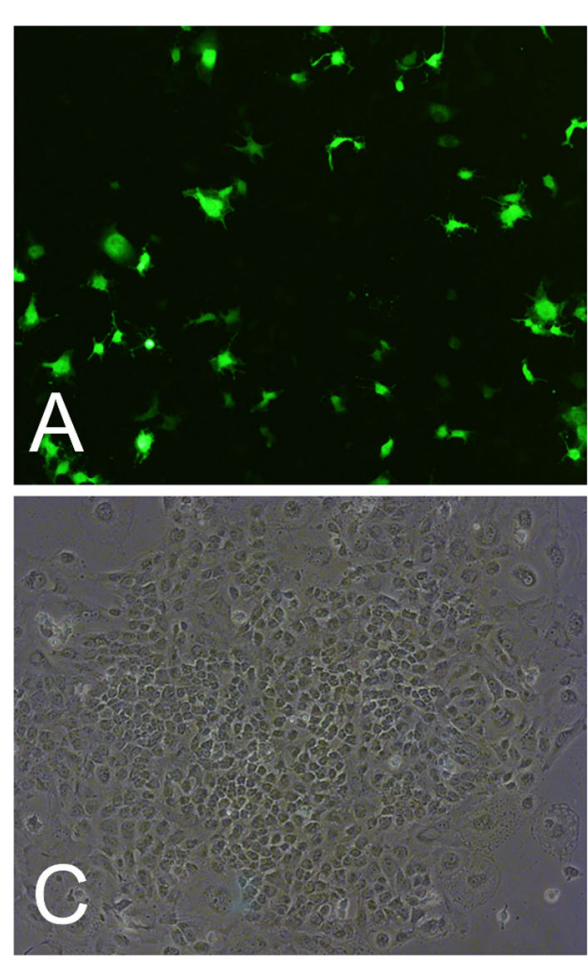

Fig. 1 Intestinal epithelial cells infected with lentivirus and screened $(\times 100)$. a Cells observed by fluorescence microscopy 5 days post-infection. b Cells observed by fluorescence
Morphology of TIEC1

Cells obtained by culturing with collagenase XI, neutral protease I, and DTT (Yin et al. 2017) were translucent when observed with an inverted microscope. After incubation for $24 \mathrm{~h}$, cell attachment was assessed. Cells maintained their shape and activity after three passages. However, after 15 passages, TIECs became hexagonal or irregular polygons with translucent cytoplasm, clear cell boundaries, and a typical "cobblestone"-like shape. After 50 passages, cells became less regular in shape but remained tightly connected (Fig. 2a and Supplementary Fig. S1). Transmission electron microscopy used to observe TIEC microstructure revealed a large number of membrane-bound particles, rich ribosome particles, tight junction complexes, and microvilli (Fig. $2 b$ and Supplementary Fig. S2).

hTERT gene expression analysis by qRT-PCR

To determine whether the $h T E R T$ gene was integrated into IECs, we used qRT-PCR to detect hTERT gene
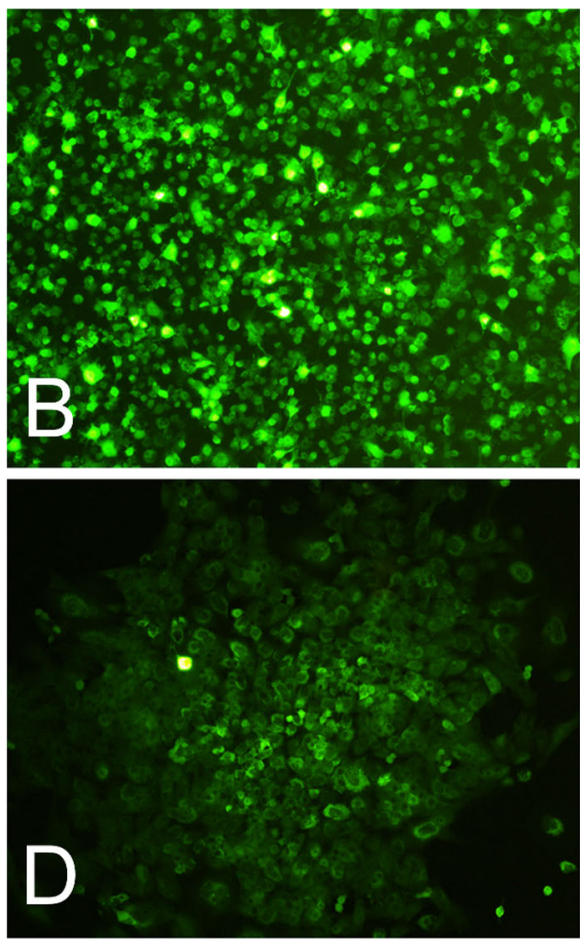

microscopy 15 days post-infection. c Monoclonal TIEC1s after screening. d Monoclonal cells observed by fluorescence microscopy 

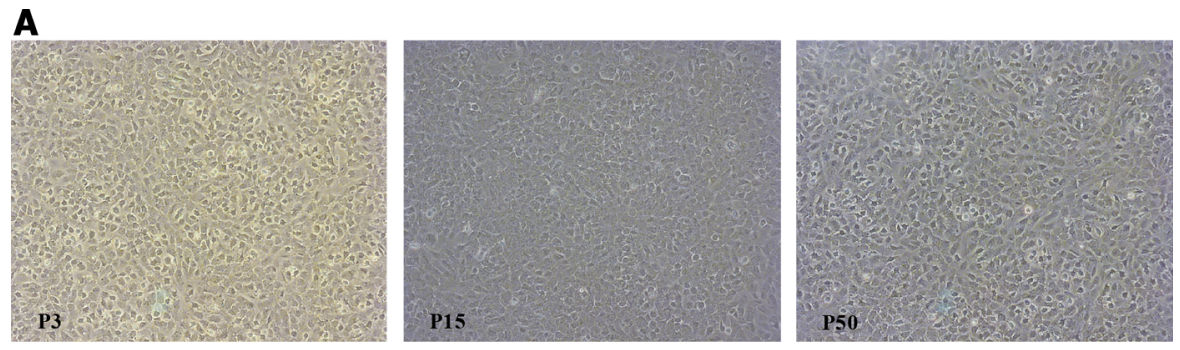

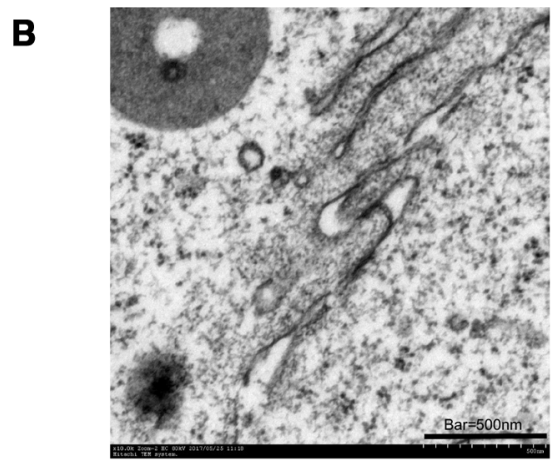

Fig. 2 Morphology of intestinal epithelial cells. a After 3 generations, pTIECs displayed a typical "cobblestone"-like shape. After 15 generations, TIEC1s became irregular polygons. After 50 generations, TIEC1s became less regular in shape but

expression in pTIECs and TIECs. Results showed that hTERT mRNA was almost undetectable in pTIECs but was detected in TIECs (Table 1), suggesting that the $h T E R T$ gene was successfully transferred into IECs and expressed in the transduced cells.

\section{TIEC1 expresses IEC-specific molecules}

TIEC1s were characterized using immunofluorescence and western blot assays. Immunofluorescence with anti-cytokeratin 18 antibodies showed that this protein was present in pTIECs, TIEC1s (Fig. 3a) and TIEC2, TIEC3 (Supplementary Fig. S3). Western blot

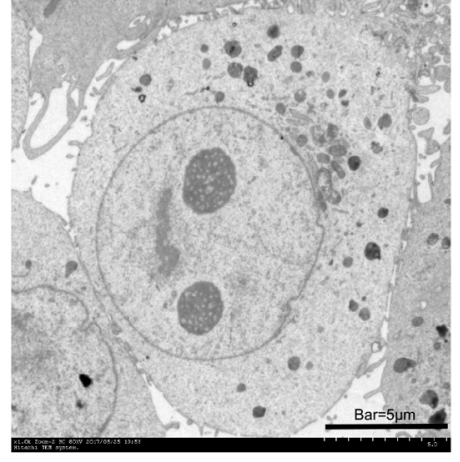

remained tightly connected $(\times 100)$. b Transmission electron microscopy of TIEC1s after 50 generations. Microvilli and tight junctions are typical features of IECs

assays with antibodies against cytokeratin 18 and the intracellular protein occludin showed that both proteins were present in TIEC1s, pTIECs (Fig. 3b) and TIEC2, TIEC3 (Supplementary Fig. S4). These results demonstrate that TIEC1s retain the characteristics of pTIECs.

The proliferative rate of TIECs is higher than that of pTIECs

In order to assess the proliferation characteristics of TIECs, growth curves were created and optimal FBS concentration assays were performed. The growth

Table 1 Quantitative reverse transcription polymerase chain reaction threshold $(\mathrm{Ct})$ values

\begin{tabular}{lllllc}
\hline Sample & pTIEC & TIEC1 & TIEC2 & TIEC3 & $P$ value \\
\hline GAPDH & $17.26 \pm 0.23$ & $17.17 \pm 0.14$ & $17.33 \pm 0.10$ & $17.07 \pm 0.43$ & NS \\
hTERT & $>40^{\mathrm{a}}$ & $33.10 \pm 0.22$ & $32.98 \pm 0.20$ & $29.61 \pm 6.54$ & - \\
\hline
\end{tabular}

Values are given as mean $\pm \mathrm{SD}$ of three independent experiments

$N S$ no statistical significant difference

${ }^{\mathrm{a}}$ Value is undetectable in 40 cycles 
Fig. 3 Biochemical characteristics of TIEC1s and pTIECs.

a Immunofluorescence staining of TIEC $1 \mathrm{~s}$ and pTIECs. The nucleus was stained with DAPI (blue) and cytokeratin 18 was stained with anti-cytokeratin 18 antibodies (red). b Detection of proteins by western blot. Cytokeratin 18 and occludin were both expressed in TIEC1s and pTIECs
A

DAPI

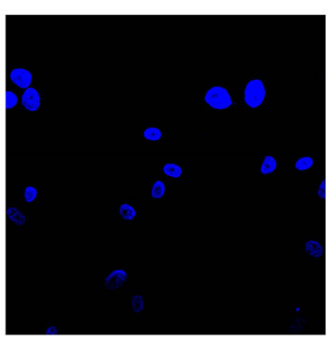

TIEC1

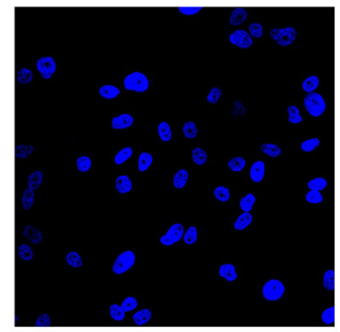

Cytokeratin 18
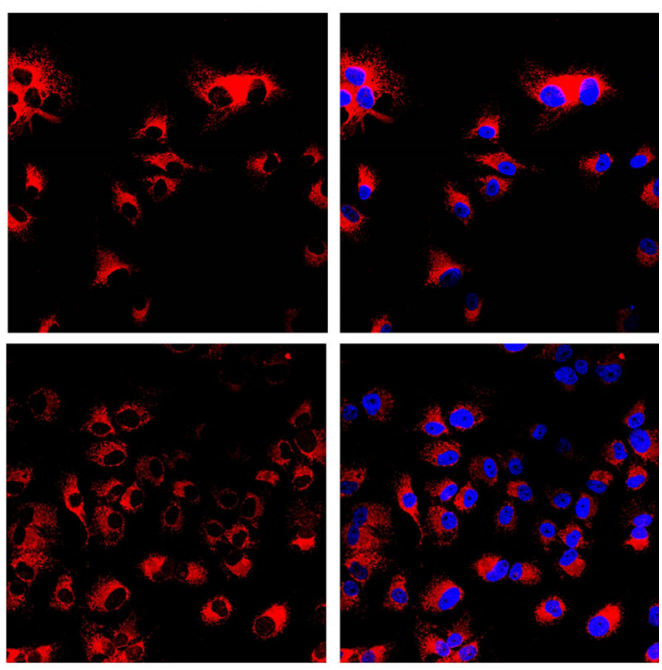

B PTIEC TIEC1

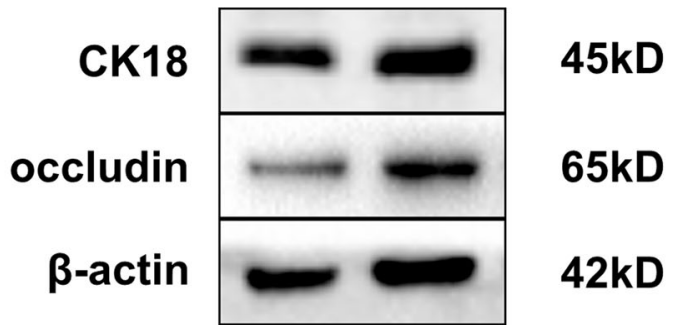

curves of pTIECs and TIECs were both S-shaped (Fig. 4a). However, the proliferation rate of TIECs was higher than that of pTIECs. The number of TIECs peaked after 5-6 days and began to decline after 7 days, whereas the number of pTIECs peaked after 7 days and began to decline after 8 days. These results suggest that TIECs had higher proliferative activity than pTIECs.

Cells were cultured with different concentrations of FBS for $36 \mathrm{~h}$ and the optical density at $450 \mathrm{~nm}$ was measured with a microplate reader. The results showed that cell proliferation was higher in media containing serum than in serum-free media (Fig. 4b). Although no significant difference in cell proliferation was observed between the different concentrations of FBS, cell proliferation was highest in cultures containing 5\% FBS.
TIECs have the same number of chromosomes as pTIECs

TIEC1s contained 62 chromosomes (Fig. 5), consistent with both pTIECs and the previously reported number of tree shrew chromosomes (Ma 2016). Similarly, TIEC1s were diploid cells, demonstrating that chromosome morphology was normal in these cells. The data of TIEC2s and TIEC3s were demonstrated in Supplementary Fig. S5.

\section{Discussion}

In this study, we established an immortalized tree shrew IEC cell line by lentivirus-mediated gene transfer of the exogenous hTERT gene. Previously, several strategies for immortalization were reported. Ma (2016) transfected the SV40Tag gene into primary 


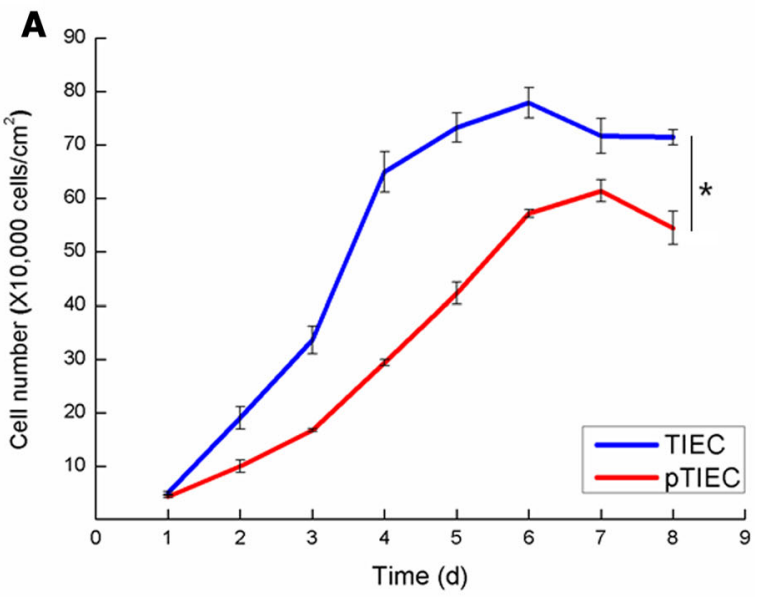

Fig. 4 Proliferation assays. Data are presented as mean \pm SD of TIEC1, TIEC2 and TIEC3. a Growth curve of pTIECs and TIECs. Both growth curves were $\mathrm{S}$-shaped and the proliferation rate of TIECs was higher than that of pTIECs. From d 2 to d8, the cell number each day of TIECs was significantly different with that of pTIECs at the 0.05 level. b Effect of FBS concentrations

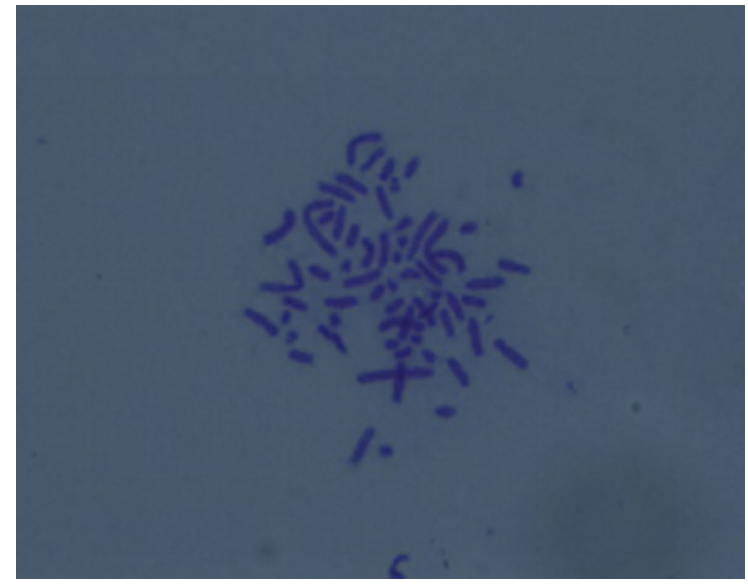

Fig. 5 Karyotype analysis of TIEC1s $(\times 1000)$. TIEC1s were diploid cells maintaining the same number of chromosomes (62) as pTIECs

tree shrew hepatocytes to establish immortalized cells. However, follow-up experiments showed that telomere length shortened as the number of passages increased. Hurlin et al. (1991) established a cell line by transfection with the HPV16 gene, but this caused a change in the genotype of the cells. The discovery of hTERT was a significant step for studies of cell proliferation, immortalization, and tumor transformation (Klingelhut 1999), as expression of the hTERT gene protects cells from telomerase activity. Maeda

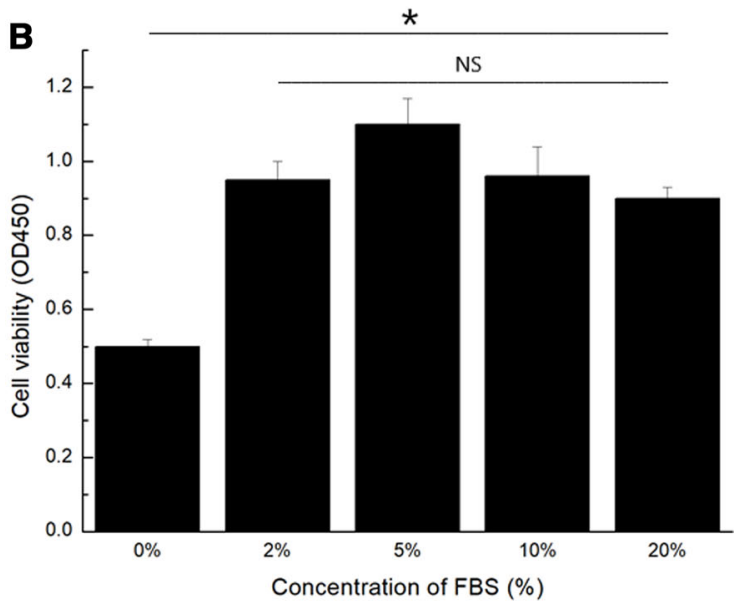

on cell viability. The cell proliferation rate in media containing $2-20 \%$ FBS was significantly different with that in FBS free media at the 0.05 level. The highest proliferation rate was observed in media containing 5\% FBS. $* p<0.05$. NS not significant

et al. (2005) successfully established five immortalized human uterine epithelial cell lines by transfecting the hTERT gene into uterine epithelial cells. This allowed for the original diploid karyotype to be maintained and did not cause a malignant phenotype. Similarly, an immortalized human liver cell line was established by Reid et al. (2009) by transfection of a recombinant retrovirus expressing the hTERT gene. These studies showed that hTERT allows primary cells to become immortalized while retaining their original cell characteristics and functions.

Previously, we transfected the exogenous $h T E R T$ gene using liposomes because their immunogenicity is lower than that of viral vectors, the size of the target gene does not affect transfection efficiency, experiments using liposomes take less time than packaging of viral vectors, and experimental material is more easily obtained from liposome transfection. However, we were unable to obtain transfected cells in these experiments. Therefore, we turned to lentivirus-mediated transduction of the exogenous $h T E R T$ gene. We also introduced a reporter gene, ZsGreen, in the lentivirus package to easily detect successfully transduced cells.

Interestingly, when we added puromycin $72 \mathrm{~h}$ postinfection, we did not obtain any positive clones. However, after optimization, we developed a protocol in which cells were cultured in a manner similar to 
primary cells for 15 days post-infection, after which positive clones could be obtained by adding puromycin. We did find that the growth rate of cells was significantly reduced after 15 days due to the addition of puromycin. Two generations after infection, uninfected cells were still present. However, as the number of passages increased, the number of uninfected cells was reduced until only transduced cells remained. At this point, the cell growth rate reached its minimum.

During our experiments, irregular cell shapes were observed and the boundaries between cells became blurred in TIEC cells. Initially, phenol red caused the cell culture media to remain red, indicating a very low cell growth rate. However, when the media were replaced every other day, the cells began to appear pebble-like and the growth rate became higher than that of primary cells. At this point, the transduced cells began to grow steadily.

Cytokeratin is a keratin intermediate filament found in the epithelial cell cytoskeleton and is often used as a marker to identify epithelial cells. Cytokeratin 18 is an epithelial cell-specific molecule that is often used to specifically identify IECs (Perreault and Beaulieu 1998; Rusu et al. 2005; Su et al. 2013). In the present study, immunofluorescence and western blot experiments showed that cytokeratin 18 was present in TIECs. Similarly, occludin is an important protein for the stability and barrier function of tight junctions (Simon-Assmann et al. 2007). IECs have been generated from undifferentiated cells in the villi of the small intestine. IECs express tight junction proteins that undifferentiated basal cells do not express that allow them to form a physical barrier in the intestinal epithelium. Our western blot experiments showed that occludin was present in TIECs, further demonstrating that TIECs are epithelial cells (Parthasarathy and Mansfield 2009). In addition, electron microscopy showed that TIECs have microvilli on their surfaces and that the cells are closely connected. These results indicate that TIECs are differentiated into villi cells and that they maintain the characteristics of epithelial cells.

The growth rate of TIECs in 5\% FBS was higher than that of pTIECs. Similar to primary cell cultures, in which $2 \%$ FBS was added to inhibit the growth of fibroblasts, transduced cells were found to proliferate poorly in the absence of FBS. Chromosome analysis showed that TIECs had 62 chromosomes, the same number that tree shrews have under normal physiological conditions. Therefore, the immortalized cell line obtained by $h T E R T$ gene transfer can be used as a method to immortalize IECs while maintaining their normal physiological properties. The hTERT gene was successfully transferred into tree shrew IECs using lentivirus and long-term stable expression of the gene was achieved. The results of qRT-PCR experiments showed that hTERT mRNA was detectable in TIECs but not pTIECs, which is in line with the results of Wang et al. (2014). In addition, results showed that telomerase activity was activated by transgenic hTERT. These transduced TIECs could be passaged in vitro for more than 50 generations owing to the successful transfer of the $h T E R T$ gene. Therefore, we conclude that $h T E R T$ gene transfer allows for the immortalization of tree shrew IECs and is a new alternative cell model for research.

Acknowledgements This work was supported by the Yunnan Science and Technology Talent and Platform Program (2017HC019); The Key Laboratory of Yunnan Province for Ophthalmic Research and Disease Control (2017DG008); and Yunnan Province Major Science and Technology Project (2017ZF007).

\section{Compliance with ethical standards}

Conflicts of interest The authors declare that there are no conflicts of interest.

Open Access This article is distributed under the terms of the Creative Commons Attribution 4.0 International License (http:// creativecommons.org/licenses/by/4.0/), which permits unrestricted use, distribution, and reproduction in any medium, provided you give appropriate credit to the original author(s) and the source, provide a link to the Creative Commons license, and indicate if changes were made.

\section{References}

Blackburn EH (2001) Switching and signaling at the telomere. Cell 106:661-673

Bodnar AG, Ouellette M, Frolkis M (1998) Extension of lifespan by introduction of telomerase into normal human cells. Science 279:349-352

Christopher Q, Zeeshan IU, Nick L, Murat E, Delphine S, Julie R, Sarah JH, Szymon TC, Joshua Q, Andrew B, Martin B, Michael B, Richard H, Paraic M, Richard KR, Christine AE, Konstantinos G (2015) Extensive modulation of the fecal metagenome in children with crohn's disease during exclusive enteral nutrition. Am J Gastroenterol 110:1718-1729. https://doi.org/10.1038/ajg.2015.357 
Codling C, O'Mahony L, Shanahan F, Quigley EMM, Marchesi JR (2010) A molecular analysis of fecal and mucosal bacterial communities in irritable bowel syndrome. Dig Dis Sci 55:392-397. https://doi.org/10.1007/s10620-0090934-X

van der Flier LG, Clevers H (2009) Stem cells, self-renewal, and differentiation in the intestinal epithelium. Annu Rev Physiol 71:241-260. https://doi.org/10.1146/annurev. physiol.010908.163145

Geens MM, Niewold TA (2011) Optimizing culture conditions of a porcine epithelial cell line IPEC-J2 through a histological and physiological characterization. Cytotechnology 63:415-423. https://doi.org/10.1007/s10616-011-9362-9

Graves CL, Harden SW, Lapato M, Nelson M, Amador B, Sorenson H, Frrazier CJ, Wallet SM (2014) A method for high purity intestinal epithelial cell culture from adult human and murine tissues for the investigation of innate immune function. J Immunol Methods 414:20-31. https:// doi.org/10.1016/j.jim.2014.08.002

Hayflick L (1965) The limited in vitro lifetime of human diploid cell strains. Exp Cell Res 37:614-636

Hurlin PJ, Kaur P, Smith PP, Perez-Reyes N, Blanton RA, McDougall JK (1991) Progression of human papillomavirus type 18 -immortalized human keratinocytes to a malignant phenotype. Proc Natl Acad Sci USA 88:570-574

Karimi G, Sabran MR, Jamaluddin R, Parvaneh K, Mohtarrudin N, Ahmad Z, Khazaai H, Khodavandi A (2015) The antiobesity effects of lactobacillus casei strain shirota versus orlistat on high fat diet-induced obese rats. Food Nutr Res 59:29273. https://doi.org/10.3402/fnr.v59.29273

Klingelhut AJ (1999) The roles of telomeres and telomerase in cellular immortalization and the development of cancer. Anticancer Res 19:4823-4830

Lynch SV, Boushey HA (2016) The microbiome and development of allergic disease. Curr Opin Allergy Clin Immunol 16:165-171. 0000000000000255

Ma N (2016) The establishment of a Tupaia hepatocyte immortalization method and characterization of Tupaia immortalized cell line ITH6.1, Peking Union Medical College, pp 74-76

Maeda T, Tashiro H, Katabuchi H, Begum M, Ohtake H, Kiyono T, Okamura H (2005) Establishment of an immortalised human ovarian surface epithelial cell line without chromosomal instability. Br J Cancer 93:116-123. https://doi. org/10.1038/sj.bjc.6602662

Martini E, Krug SM, Siegmund B, Neurath MF, Becker C (2017) Mend your fences: the epithelial barrier and its relationship with mucosal immunity in inflammatory bowel disease. Cell Mol Gastroenterol Hepatol 4:33-46. https://doi.org/10.1016/j.jcmgh.2017.03.007

Parthasarathy G, Mansfield LS (2009) Recombinant interleukin4 enhances campylobacter Jejuni invasion of intestinal pig epithelial cells (ipec-1). Microb Pathog 47:38-46. https:// doi.org/10.1016/j.micpath.2009.04.011

Perreault N, Beaulieu JF (1998) Primary cultures of fully differentiated and pure human intestinal epithelial cells. Exp Cell Res 245:34-42. https://doi.org/10.1006/excr.1998. 4221

Reid Y, Gaddipati JP, Yadav D, Kantor J (2009) Establishment of a human neonatal hepatocyte cell line. Vitro Cell Dev Biol Anim 45:535-542. https://doi.org/10.1007/s11626009-9219-0

Rusu D, Loret S, Peulen O, Mainil J, Dandrifosse G (2005) Immunochemical, biomolecular and biochemical characterization of bovine epithelial intestinal primocultures. BMC Cell Biol 6:42-53. https://doi.org/10.1186/14712121-6-42

Simon-Assmann P, Turck N, Sidhoum-Jenny M, Gradwohl G, Kedinger M (2007) In vitro, models of intestinal epithelial cell differentiation. Cell Biol Toxicol 23:241-256. https:// doi.org/10.1007/s10565-006-0175-0

Su F, Liu X, Liu G, Yu Y, Wang Y, Jin Y, Hu G, Hua S, Zhang Y (2013) Establishment and evaluation of a stable cattle type ii alveolar epithelial cell line. PLoS ONE 8:e76036. https:// doi.org/10.1371/journal.pone.0076036

Tanaka M, Nakayama J (2017) Development of the gut microbiota in infancy and its impact on health in later life. Allergol Int 66:515-522. https://doi.org/10.1016/j.alit. 2017.07.010

Wang Y, Kasper LH (2014) The role of microbiome in central nervous system disorders. Brain Behav Immun 38:1-28. https://doi.org/10.1016/j.bbi.2013.12.015

Wang J, Hu G, Lin Z, He L, Xu L, Zhang Y (2014) Characteristic and functional analysis of a newly established porcine small intestinal epithelial cell line. PLoS ONE 9:e110916. https://doi.org/10.1371/journal.pone.0110916

Witzany G (2008) The viral origins of telomeres and telomerases and their important role in eukaryogenesis and genome maintenance. Biosemiotics 1:191-206

Xu L, Chen SY, Nie WH, Jiang XL, Yao YG (2012) Evaluating the phylogenetic position of chinese tree shrew (tupaia belangeri chinensis) based on complete mitochondrial genome: implication for using tree shrew as an alternative experimental animal to primates in biomedical research. J Genet Genom 39:131-137. https://doi.org/10.1016/j.jgg. 2012.02.003

Xu L, Zhang Y, Liang B, Lv L, Chen C, Chen Y, Zhou C, Yao Y (2013) tree shrews under the spot light: emerging model of human diseases. Zool Res 34:59-69. https://doi.org/10. 3724/SP.J.1141.2013.02059

Yin B, Chen L, Li Z, Li X, Song Q, Miao Y, Sun X (2017) Culture and identification of intestinal epithelial cells isolated from tree shrew in vitro. Lab Anim Sci 34:11-15 